\section{Correspondence on 'Haemodynamic phenotypes and survival in patients with systemic sclerosis: the impact of the new definition of pulmonary arterial hypertension'}

The 6th World Symposium of pulmonary hypertension has proposed to widen the definition of pulmonary arterial hypertension (PAH) identifying a lower cut-off for mean pulmonary arterial pressure (mPAP) from $\geq 25 \mathrm{~mm} \mathrm{Hg}$ (as recommended by the actual guidelines) to $>20 \mathrm{~mm} \mathrm{Hg}$, in combination with pulmonary vascular resistance (PVR) $\geq 3$ Wood units (WU).

In general, a change in the formal definition of a disease can impact in many different ways how the patients are identified, treated, and their prognosis. One of the consequence of such redefinition in patients with systemic sclerosis (SSc) has been addressed by Xanthouli et al, in their very interesting and original paper. ${ }^{1}$ The authors have shown that since most patients with SSc with an mPAP 21-24 mm Hg have PVR $<3$ WU, if left unmodified, the new criteria could allow to reclassify as PAH only $8 \%$ of mPAP 21-24 mm Hg patients, despite they display a pulmonary vascular disease and a poor prognosis. This paper, focusing on one aspect related to disease redefinition, has prompted us to add further general comments on what we should consider when future observational research will compare samples of patients identified by a more strict (current criteria for PAH in this case) or broader (new proposed criteria) disease definition, keeping in mind that the latter group include by definition (a) a larger number of patients, (b) likely to receive a diagnosis earlier and (c) with an average milder disease.

First, the validity of survival analyses comparing cohorts of patients defined according to an 'old' versus a 'broadened new' definition can be threatened if biased analyses are performed. Let's assume we want to compare the survival of patients with SSc-PAH diagnosed according to the current (figure 1, patient 1) versus the new proposed criteria (figure 1 , patient 2 ) in an observational setting, hypothesising that the true survival time and mPAP evolution over time of both patients are exactly the same. Assuming that the screening strategies to select patients with SSc for right heart catheterisation remain the same over time, patient 2 will likely receive a diagnosis of PAH earlier. If we calculate the survival time from the date of diagnosis, an additional time period is added by the use of new criteria, which is the time during which mPAP increased from $21 \mathrm{~mm} \mathrm{Hg}$ (lower limit of the proposed new definition) to $25 \mathrm{~mm} \mathrm{Hg}$ (the lower limit of the current definition), which is called lead time. For a fair comparison of survival, this time period should be discarded from the survival time of patient $2 .^{23}$ If we do not adjust for the lead time, we can erroneously estimate a longer survival for patients 2 compared with that of patient 1 . This phenomenon is well known in cancer screening. ${ }^{4}$

Therefore, the comparison of survival involving 'old' and 'new' definitions of PAH should be conducted using adequate methods to correct lead time bias. This can be performed by subtracting an estimate of the lead time bias obtained in a multistate model with simple-possibly unrealistic-assumptions, ${ }^{5}$ or more complex models of the mPAP measurement process, akin to the use of tumour growth models in cancer screening. ${ }^{6}$ Models adjusted for the age, and/or calendar-matched population can also allow to overcome this potential problem.

Second, by using the new criteria, PAH cohorts will include also patients with lower values of mPAP, who are less ill, and
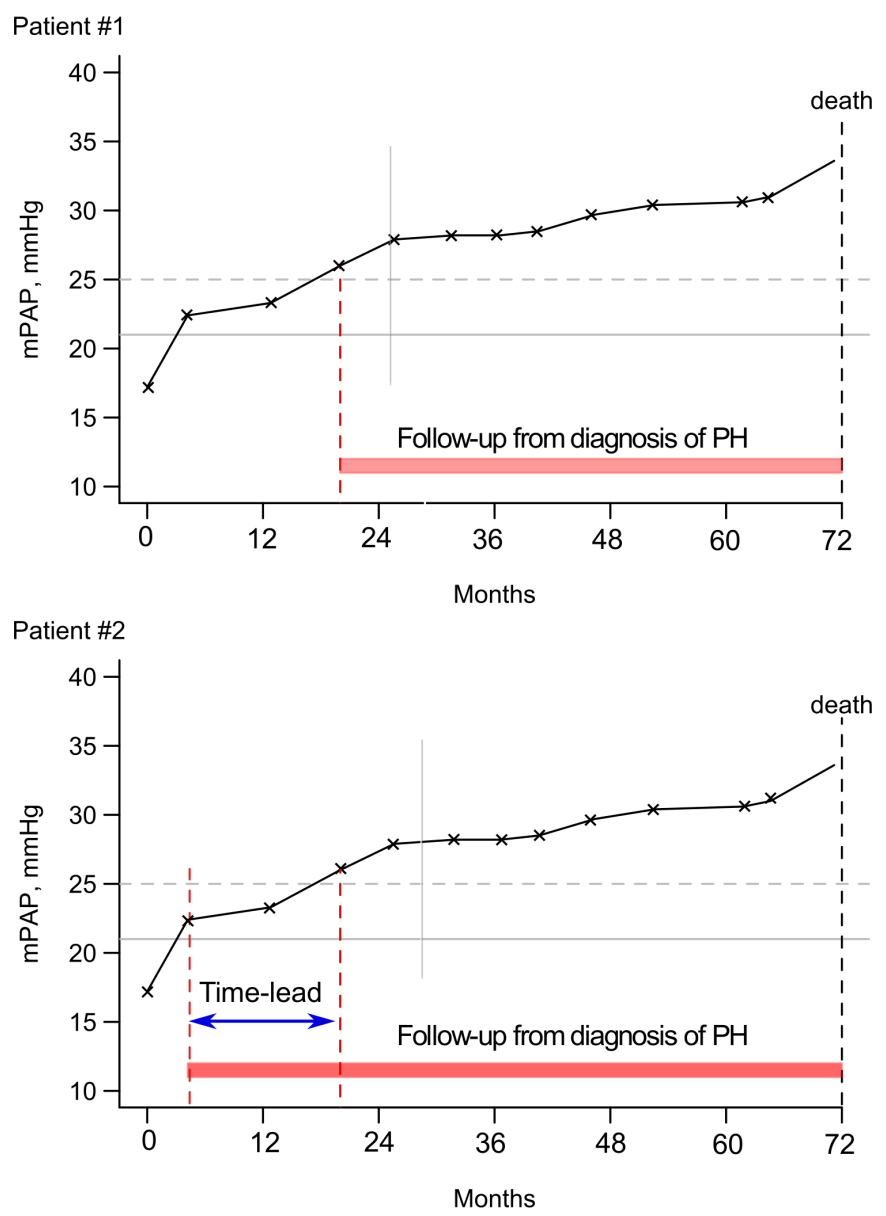

Figure 1 Lead time bias. Each patient survived the same time from an equivalent starting point of mean pulmonary arterial pressure (mPAP). Illustration of a lead time bias occurring when survival time is calculated from the diagnosis according to the current (patient 1), or the new proposed (patient 2) criteria for the diagnosis of pulmonary hypertension (PH).

would not necessarily develop a severe disease in the shortterm and mid-term. Actually, studies on patients with SSc with borderline PAH (mPAP between 21 and $24 \mathrm{~mm} \mathrm{Hg}$ ) have shown that an increase of mPAP above $25 \mathrm{~mm} \mathrm{Hg}$ only occurs in about onethird of cases within 5 years. ${ }^{78}$ Therefore, the simple incorporation in the 'diseased' group of patients with a milder PAH, although already having a clinically meaningful pulmonary vascular disease, right ventricle dysfunction and reduced longterm survival, ${ }^{9}$ dilutes the disease severity of the 'redefined PAH' group. This aspect should be considered in order not to artifactually ascribe to the new diagnostic strategy a causal link with the observed better outcome.

Finally, even if in the context of SSc this proposed new definition is likely to reclassify a small number of patients as having $\mathrm{PAH}^{1}{ }^{10}$ an increased $\mathrm{PAH}$ prevalence/incidence recorded in next years, even limited, is expected, and should be interpreted in the context of this lower threshold for diagnosing PAH.

In conclusion, practical and methodological aspects can arise from a disease redefinition, ranging from the risk of not including all patients potentially taking benefit from receiving a diagnosis earlier as shown by Xanthouli et al, ${ }^{1}$ to the potential pitfalls that can occur in observational research carried out in patients identified by different criteria.

Michele ludici $\odot,{ }^{1}$ Danièle Allali, ${ }^{2}$ Raphaël Porcher ${ }^{3}$ 
${ }^{1}$ Rheumatology Unit, Geneva University Hospitals and University of Geneva, Geneva, Switzerland

${ }^{2}$ Department of Internal Medicine Specialties, Immunology and Allergy, University Hospital and School of Medicine, Geneva, Switzerland

${ }^{3}$ Methods of Therapeutic Evaluation Of Chronic Diseases (METHODS) team, INSERM UMR 1153, Epidemiology and Biostatistics Sorbonne Paris Cité Research Center (CRESS), Paris, France

Correspondence to Dr Michele ludici, Rheumatology Unit, Geneva University Hospitals and University of Geneva, Geneva, Switzerland; michele.iudici@hcuge.ch

Contributors MI, DA, RP were responsible for the conception of the study, and manuscript writing.

Funding The authors have not declared a specific grant for this research from any funding agency in the public, commercial or not-for-profit sectors.

Competing interests None declared.

Patient and public involvement Patients and/or the public were not involved in the design, or conduct, or reporting, or dissemination plans of this research.

Patient consent for publication Not required.

Provenance and peer review Not commissioned; internally peer reviewed.

(C) Author(s) (or their employer(s)) 2020. No commercial re-use. See rights and permissions. Published by BMJ.

\section{A) Check for updates}

To cite ludici M, Allali D, Porcher R. Ann Rheum Dis Epub ahead of print: [please include Day Month Year]. doi:10.1136/annrheumdis-2020-219568

Received 23 November 2020

Accepted 25 November 2020

\section{S Linked}

https://doi.org/10.1136/annrheumdis-2020-219597

Ann Rheum Dis 2020:0:1-2. doi:10.1136/annrheumdis-2020-219568

\section{ORCID iD}

Michele ludici http://orcid.org/0000-0001-5871-8806

\section{REFERENCES}

1 Xanthouli P, Jordan S, Milde N, et al. Haemodynamic phenotypes and survival in patients with systemic sclerosis: the impact of the new definition of pulmonary arterial hypertension. Ann Rheum Dis 2020;79:370-8.

2 Kramer BS, Croswell JM. Cancer screening: the clash of science and intuition. Annu Rev Med 2009;60:125-37.

3 Croswell JM, Ransohoff DF, Kramer BS. Principles of cancer screening: lessons from history and study design issues. Semin Oncol 2010;37:202-15.

4 Independent UK Panel on Breast Cancer Screening. The benefits and harms of breast cancer screening: an independent review. Lancet 2012;380:1778-86.

5 Duffy SW, Nagtegaal ID, Wallis M, et al. Correcting for lead time and length bias in estimating the effect of screen detection on cancer survival. Am J Epidemiol 2008;168:98-104.

6 Abrahamsson L, Isheden G, Czene K, et al. Continuous tumour growth models, lead time estimation and length bias in breast cancer screening studies. Stat Methods Med Res 2020;29:374-95

7 Coghlan JG, Wolf M, Distler 0 , et al. Incidence of pulmonary hypertension and determining factors in patients with systemic sclerosis. Eur Respir J 2018;51. doi:10.1183/13993003.01197-2017. [Epub ahead of print: 04 Apr 2018].

8 Valerio CJ, Schreiber BE, Handler CE, et al. Borderline mean pulmonary artery pressure in patients with systemic sclerosis: transpulmonary gradient predicts risk of developing pulmonary hypertension. Arthritis Rheum 2013;65:1074-84.

9 Nagel C, Marra AM, Benjamin N, et al. Reduced right ventricular output reserve in patients with systemic sclerosis and mildly elevated pulmonary artery pressure. Arthritis Rheumatol 2019;71:805-16.

10 Jaafar S, Visovatti S, Young A, et al. Impact of the revised haemodynamic definition on the diagnosis of pulmonary hypertension in patients with systemic sclerosis. Eur Respir J 2019;54:1900586. 